\title{
DETERMINATION OF WEIBULL PARAMETERS FOR WIND APPLICATIONS IN TWO DIFFERENT REGIONS
}

\author{
W. F. A. Borges, \\ A. M. Araújo, \\ ABSTRACT \\ O. D. Q. de Oliveira Filho, \\ In this work, the main objective is to determine the shape $(k)$ and scale $(c)$ \\ parameters of the Weibull probability density function through four \\ numerical methods, known as graphical method (GM), empirical method of \\ Justus (EMJ), empirical method of Lysen (EML), and moment method \\ (MM) in two distinct cities, Gravatá-PE and Osório-RS, under the influence \\ of two wind regimes. To do that, it will be used the hourly wind data \\ obtained through NASA's Meteonorm database, from 2006 to 2015. \\ Statistical analyzes also will be used to determine the best method used to \\ Universidade Federal de Pernambuco \\ Departamento de Engenharia Mecânica \\ determine these parameters. \\ Programa de Pós-Graduação em \\ Engenharia Mecânica - PPGEM/UFPE \\ Avenida Prof. Moraes Rêgo, 1235 \\ Bairro Cidade Universitária \\ CEP 50670-901, Recife, Pernambuco, Brasil \\ wenio.borges@ufpe.br \\ Received: May 24, 2018 \\ Revised: June 11, 2018 \\ Accepted: July 12, 2018 \\ Keywords: Weibull distribution; parameters; wind
}

\section{NOMENCLATURE}

$c \quad$ scale parameter, $\mathrm{m} / \mathrm{s}$

CDF cumulative density function, Eq. (1)

EMJ empirical method of Justus, Eq. (8)

EML empirical method of Lysen, Eq. (9)

GM graphical method, Eq. (7)

MM moment method, Eq. (10)

$\mathrm{n}$ number of intervals, Eq. (11-12)

$k \quad$ shape parameter, dimensionless

PDF probability density function, Eq. (5)

$V \quad$ velocity, $\mathrm{m} / \mathrm{s}$

$V_{m} \quad$ mean wind speed, $\mathrm{m} / \mathrm{s}$

$\mathrm{S}$ south, $\left({ }^{\circ}\right)$

W west, $\left({ }^{\circ}\right)$

$x_{i} \quad$ obtained of Weibull distribution, Eq. (11-12)

$\bar{y} \quad$ mean of the $y_{i}$ values, Eq. (11)

$y_{i} \quad$ wind velocity data frequency, Eq. (11-12)

\section{Greek symbols}

$\Gamma \quad$ gamma function, Eq. (4)

$\sigma \quad$ standard deviation of wind speed data, $\mathrm{m} / \mathrm{s}$

\section{INTRODUCTION}

Brazil has three main regions with great potential for wind power generation. The largest one is located in the Northeast region, where the theoretical wind potential is around $75 \mathrm{GW}$ for at the nacelle's height of $50 \mathrm{~m}$. The other two regions are the Southeast (with $29.7 \mathrm{GW}$ ) and the South (with 22.8 GW), and these values could double considering heights of 80 and 100m (Pes et al., 2017).

The main wind regimes, which predominate in Brazil, are the trade winds, which are winds that occur between $0^{\circ}$ (equator line) and $30^{\circ}$ latitude, and the westerlies winds, which occur between $30^{\circ}$ and $60^{\circ}$ latitude. The influences of these two regimes provide good potential for wind power generation in the northeast and south regions of the country.

Several studies related to wind power focus on the problem of adjusting statistical distributions to wind speed data. Thus, it was verified through studies that, for most wind occurrences, the Weibull distribution provides a good fit (Oliveira Filho et al., 2017; Usta, 2016; Bagiorgas et al., 2015; Rehman et al., 2012; Bagiorgas et al., 2011).

In this work, the main objective is to determine the shape $(k)$ and scale $(c)$ parameters of the Weibull probability density function through four numerical methods, known as graphical method (GM), empirical method of Justus (EMJ), empirical method of Lysen (MEL) and moment method (MM) in two distinct locations, Gravatá-PE and Osório-RS, under the influence of two wind regimes.

\section{METHODOLOGY}

The wind velocity distribution is modeled by 
the Weibull function, which is a two-parameter function whose cumulative density function (CDF), is mathematically described as (Lysen, 1983):

$$
F(V)=1-\exp \left[-\left(\frac{V}{c}\right)^{k}\right]
$$

where $k$ and $c$ are the shape and scale parameters, respectively. The shape parameter determines the shape of the Weibull distribution curve. This reveals the regularity of the winds, that is, for greater values of $k$, winds will present greater regularities in terms of velocity, and the distribution curve has a narrow format, the scale parameter $c$ is the characteristic factor of the distribution (Kumaravel et al., 2014).

The CDF indicates the probability of finding a velocity value between 0 and $V$. By multiplying this value by the number of hours of the period in which the data were collected, one has the fraction of the time in which the velocity remained between the two values.

The probability density function (PDF), represents the fraction of time that the wind speed is centered in an interval of $1 \mathrm{~m} / \mathrm{s}$ in $V$ (Manwell et al., 2009), and is written as $f(V)=d F(V) / d V$, resulting in:

$$
f(V)=k \frac{V^{k-1}}{c^{k}} \exp \left[-\left(\frac{V}{c}\right)^{k}\right]
$$

where $\mathrm{k}>0, \mathrm{~V}>0$ and $\mathrm{c}>1$ (Johnson, 2001).

The average wind speed, $V_{m}$, of the Weibull function can be obtained through the gamma function:

$$
V_{m}=c \Gamma\left(1+\frac{1}{k}\right)
$$

where the gamma function $\Gamma(x)$, for $x>0$, is defined as (Devore, 2006):

$$
\Gamma(x)=\int_{0}^{\infty} e^{-t} t^{x-1} d t
$$

In this way, we can express $F(V)$ and $f(V)$, respectively, as:

$$
\begin{gathered}
F(V)=1-\exp \left[\Gamma^{k}\left(1+\frac{1}{k}\right)\left(\frac{V}{V_{m}}\right)^{k}\right] \\
f(V)=\left(\frac{k}{V}\right)\left(\frac{k}{V_{m}}\right)^{k} \cdot \Gamma^{k}\left(1+\frac{1}{k}\right) \cdot \exp \left[-\Gamma^{k}\left(1+\frac{1}{k}\right)\left(\frac{V}{V_{m}}\right)^{k}\right]
\end{gathered}
$$

The wind data used in this study were obtained from NASA's Meteonorm database (NASA, 2017).
Winds velocities are measured at the high of $50 \mathrm{~m}$. Table 1 shows the geographical location of the selected locations.

Table 1. Geographic location of the studied cities and their elevation.

\begin{tabular}{|c|c|c|}
\hline Location & Latitude & Longitude \\
\hline Gravatá-PE & $08^{\circ} 1^{\prime}(\mathrm{S})$ & $35^{\circ} 3^{\prime}(\mathrm{W})$ \\
\hline Osório-RS & $29^{\circ} 5^{\prime}(\mathrm{S})$ & $50^{\circ} 2^{\prime}(\mathrm{W})$ \\
\hline
\end{tabular}

\section{METHODS FOR DETERMINATION OF WEIBULL PARAMETERS}

\section{(i) Graphical method (GM)}

The graphical method is obtained through the cumulative density function. If we calculate the twice $\log$ of the CDF, Eq 1, it will become a first degree equation, of the type $y=a x+b$, where $\ln [-\ln [1-F$ (v)]] is on the $y$-axis, and the $\ln (v)$ is on the $x$-axis, $k$ is the slope of the line (Mohammadi et al., 2016; Akdag and Dinler, 2009). The coefficients $a$ and $b$ of the line can be obtained as shown:

$$
\begin{aligned}
\ln [-\ln [1-F(v)]] & =k \cdot \ln (v)-k \cdot \ln (c) \\
y & =a \cdot x+b
\end{aligned}
$$

where: $\begin{aligned} & a=k \\ & b=-k \cdot \ln c \Rightarrow c=\exp (-b / k)\end{aligned}$

\section{(ii) Empirical Method of Justus (EMJ)}

The empirical method of Justus was introduced by Justus in 1977. It presents a direct solution based on the average wind speed $\left(V_{m}\right)$ and the standard deviation $(\sigma)$ (Mohammadi et al., 2016). Both parameters, $k$ and $c$, are obtained as:

$$
k=\left(\frac{\sigma}{V_{m}}\right)^{-1.086} \text { and } V_{m}=c \Gamma\left(1+\frac{1}{k}\right)
$$

\section{(iii) Empirical method of Lysen (EML)}

The empirical method of Lysen was introduced by Lysen in 1983. The calculation of the parameter of form $k$ is equal to that of the Justus method (EMJ) with the difference in the calculation of the scale parameter $c$ (Mohammadi et al., 2016).

$$
\begin{gathered}
k=\left(\frac{\sigma}{V_{m}}\right)^{-1.086} \text { and } \\
c=V_{m}\left(0.568+\frac{0.433}{k}\right)-\frac{1}{k}
\end{gathered}
$$

\section{(iv) Moment Method (MM)}

The moment method was introduced by Justus 
and Mikhail (1976), the same ones who developed the graphical method. This method is based on the mean wind speed $\left(V_{m}\right)$ and the standard deviation $(\sigma)$, however, the parameters $k$ and $c$ are found through the iterative solution of:

$$
\begin{gathered}
V_{m}=c \Gamma\left(1+\frac{1}{k}\right) \text { and } \\
\sigma=c\left[\Gamma\left(1+\frac{2}{k}\right)-\Gamma^{2}\left(1+\frac{1}{k}\right)\right]^{\frac{1}{2}}
\end{gathered}
$$

\section{STATISTICAL ANALYSIS OF THE DIFFERENT METHODS}

Two statistical techniques were used in order to determine the accuracy of the Weibull parameters between the experimental/observed and calculated data, they are (Katinas et al., 2017; Mohammadi et al., 2016):

(a) Coefficient of determination $\left(\mathrm{R}^{2}\right)$

$$
R^{2}=1-\frac{\sum_{i=n}^{n}\left(y_{i}-x_{i}\right)^{2}}{\sum_{i=n}^{n}\left(y_{i}-\bar{y}\right)^{2}}
$$

(b) Root mean square error (RMSE)

$$
R M S E=\left[\frac{1}{n} \sum_{i=n}^{n}\left(y_{i}-x_{i}\right)^{2}\right]^{\frac{1}{2}}
$$

where $n$ is the total number of intervals, $y_{i}$ is the observed wind velocity data frequency, $x_{i}$ is the value calculated from the Weibull distribution, and $\bar{y}$ is the mean of the $y_{i}$ values.

\section{RESULTS AND DISCUSSIONS}

In this study, the parameters $k$ e $c$ of the Weibull probability density function for the cities of GravatáPE and Osório-RS were determined from hourly wind speed data for the period from 2006 to 2015 . The maximum wind speed found for Gravatá-PE was equal to $11.94 \mathrm{~m} / \mathrm{s}$, the average equal to $6.05 \mathrm{~m} / \mathrm{s}$ and the standard deviation equal to $1.27 \mathrm{~m} / \mathrm{s}$. For Osório$\mathrm{RS}$, the maximum wind speed was equal to 17.16 $\mathrm{m} / \mathrm{s}$, the average equal to $4.92 \mathrm{~m} / \mathrm{s}$ and the standard deviation equal to $2.07 \mathrm{~m} / \mathrm{s}$.

Table 2 presents the results obtained from the application of the four numerical methods used to determine the $k$ and $c$ parameters of the Weibull distribution for Gravatá-PE.

Table 2. Values of $k$ and $c$ for Gravatá-PE.

\begin{tabular}{|c|c|c|}
\hline & $\boldsymbol{k}$ & $\boldsymbol{c}$ \\
\hline GM & 5.0105 & 6.2676 \\
\hline EMJ & 5.4290 & 6.5584 \\
\hline EML & 5.4290 & 6.5540 \\
\hline MM & 5.4575 & 6.5564 \\
\hline
\end{tabular}

Table 3 presents the results obtained from the wind speed data for the same period considered in Gravatá-PE, which was from 2006 to 2015 . This case is for Osório-RS.

Table 3. Values of $k$ and $c$ for Osório-RS.

\begin{tabular}{|c|c|c|}
\hline \multirow{2}{*}{ Methods } & \multicolumn{2}{|c|}{ Weibull parameters } \\
\cline { 2 - 3 } & $\boldsymbol{k}$ & $\boldsymbol{c}$ \\
\hline GM & 2.3869 & 4.8568 \\
\hline EMJ & 2.5591 & 5.5364 \\
\hline EML & 2.5590 & 5.5372 \\
\hline MM & 2.5506 & 5.5369 \\
\hline
\end{tabular}

Figure 1 shows the result of applying the graphical method to obtain the parameters $k$ and $c$ for Osório-RS. The values of $a$ and $b$ of the line are related according to Eq. 7, as shown previously,

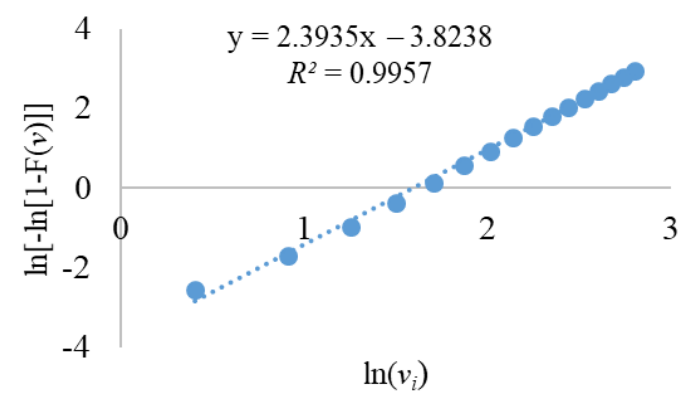

Figure 1. Application of the graphical method for Osório-RS.

Statistical analysis showed that for Gravatá-PE, the graphical method was the one that presented the best result for the parameters of Weibull, $k$ and $c$. On the other hand, in the case of Osório-RS, the graphical method was the one that demonstrated the worst result, being the method of the moment the one that provided the best result.

\section{CONCLUSIONS}

The parameters $k$ and $c$ of the Weibull probability density function were determined by applying four different methods in order to characterize the wind regime of two cities located in two different regions under different wind regimes. A statistical analysis determined which of the methods used presented the values of $k$ and $c$ that best characterize the region. For Gravatá-PE, the graphical method (GM) presented the best performance according to the two statistical models used, for the second case, Osório-RS, the moment method (MM) presented the best performance. 


\section{ACKNOWLEDGEMENTS}

The authors would like to acknowledge the Graduate Program in Mechanical Engineering at the Federal University of Pernambuco (PPGEM/UFPE), CAPES and CNPq for supporting this work. In addition, we are grateful to the help of all colleagues involved in this work.

\section{REFERENCES}

Akdag, S. A., and Dinler, A., 2009, A New Method to Estimate Weibull Parameters for Wind Energy Applications, Energy Conversion and Management, Vol. 50, pp. 1761-1766.

Bagiorgas, H. S., Gioulli, M., Rehman, S., and Al-Hadhrami, L. M., 2011, Weibull Parameters Estimation Using Four Different Methods and Most Energy-Carrying Wind Speed Analysis, International Journal of Green Energy, Vol. 8, pp. 529-554.

Bagiorgas, H. S., Gioulli, M., Rehman, S., and Al-Hadhrami, L. M., 2015, Wind Power Potential Assessment for Three Buoys Data Collection Stations in the Ionian Sea Using Weibull Distribution Function, International Journal of Green Energy, Vol. 13, pp. 703-714.

Devore, J. L., 2006, Probability and Statistics for Engineering and the Science, 6th Edition, Thomson.

Johnson, G. L., 2001, Wind Energy Systems, Electronic Edition, Manhattan, Kansas State University.

Justus, C. G., and Mikhail, A., 1976, Height Variation of Wind Speed and Wind Distribution Statistics, Geophysical Research Letters, Vol. 3, pp. 261-264.

Katinas, V., Marčiukaitis, M., Gecevičius, G., and Markevičius, A., 2017, Statistical Analysis of Wind Characteristics Based on Weibull Methods for Estimation of Power Generation in Lithuania, Renewable Energy, Vol. 113, pp. 190-201.

Kumaravel, R., Varun, C., and Sarfudeen, M., 2014, Mixed Weibull Distribution: a Case Study on Ichanda, India, Wind Engineering, Vol. 38, pp. 613620.

Lysen, E. H., 1983, Introduction to Wind Energy, 2nd edition, CWD-Consultancy Services Wind Energy Developing Countries.

Manwell, J. F., McGowan, J. G., and Rogers, A. L., 2009, Wind Energy Explained: theory, Design and Application, 2nd edition, John Wiley \& Sons.

Mohammadi, K., Alavi, O., Mostafaeipour, A., Goudarzi, N., and Jalilvand, M., 2016, Assessing Different Parameters Estimation Methods of Weibull Distribution to Compute Wind Power Density, Energy Conversion and Management, Vol. 108, pp. 322-335.

Oliveira Filho, O. D. Q., Araújo, A. M., Andrade, L. I., Silva, A. A. C., Bezerra, C. C. A., Fernandes, E. C. R., Rocha, E. J. F., Rocha, G. J. A.
M., and Borges, W. F. A., 2017, Analysis of Weibull Parameters for Wind Power Generation, in: 24th Brazilian Congress of Mechanical Engineering, Proceeding of COBEM 2017, Curitiba, Paraná.

Pes, M. P., Pereira, E. B., Marengo, J. A., Martins, F. R., Heinemann, D., and Schmidt, M., 2017, Climate Trends on the Extreme Winds in Brazil, Renewable Energy, Vol. 109, pp. 110-120.

Rehman, S., Mahbub Alam, A. M., Meyer, J. P., and Al-Hadhrami, L. M., 2012, Wind Speed Characteristics and Resource Assessment Using Weibull Parameters, International Journal of Green Energy, Vol. 9, pp. 800-814.

Usta, I., 2016, An Innovative Estimation Method Regarding Weibull Parameters for Wind Energy Applications, Energy, Vol. 106, pp. 301-314. 